\title{
Evaluation of Patient Radiation Doses in Skull Radiography
}

\author{
Chanchal Kaushik ${ }^{1 *}$, Inderjeet Singh Sandhu ${ }^{2}$ and AK Srivastava ${ }^{3}$ \\ ${ }^{1}$ Chitkara School of Health Sciences, Chitkara University, Punjab-140401, India \\ ${ }^{2}$ Chitkara University Institute of Engineering \& Technology, Chitkara University, Punjab-140401, India \\ ${ }^{3}$ Department of Radiology, University College of Medical Sciences, Delhi-110095, India
}

"Email: chanchal.kaushik@chitkara.edu.in

\section{ARTICLE INFORMATION}

Received: October 12, 2018

Revised: December 20, 2018

Accepted: January 24, 2019

Published Online: April 08, 2019

\section{Keywords:}

Quality assurance and quality control,

Skull X-ray, digital radiography,

entrance surface air kerma, effective dose,

diagnostic reference levels

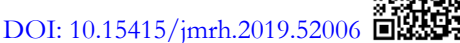

\section{ABSTRACT}

Purpose: Exposures to medical ionizing radiations elevate the risk of stochastic effects such as cancer in exposed individuals. It is of utmost importance to monitor the radiation doses delivered to patients and their optimization to reduce the associated radiation risks without limiting the diagnostic information.

Methods: Entrance surface air kerma (ESAK) in a total of 64 adult patients in diagnostic digital Xray examinations were calculated and effective doses were estimated as per International Atomic Energy Agency (IAEA).

Results: Median ESAK (mGy) and associated effective doses obtained were skull PA ( $0.45 \mathrm{mGy}$, $0.005 \mathrm{mSv})$ and skull Lat $(0.25 \mathrm{mGy}, 0.003 \mathrm{mSv})$. Results were compared with UK diagnostic reference levels and studies in India.

Conclusion: The comparison revealed that the calculated ESAK and effective dose values were less than the published literature. ESAK values reported in this study could further contribute to establishing LDRLs.

\section{Introduction}

Medical ionizing exposures elevate the risk of stochastic effects in exposed individuals (Hall et al., 2005). National and international bodies such as National Radiological Protection Board (NRPB), Atomic Energy Regulatory Board (AERB), European Commission (EC), International Atomic Energy Agency (IAEA) and International Commission on Radiological Protection (ICRP) have recommended the establishment of diagnostic reference levels (DRLs) (IAEA, 2005; Hart, 2002; Gray, 2005). They suggest calculation of patient radiation doses and their comparison with DRLs (Vano et al., 2017). DRLs can be local, regional and national. International bodies in radiation protection suggests each country to set up their own DRLs and update them periodically. Also, due to the technological advancements, there has been a shift from the film-screen radiography to the digital radiography (DR) in recent years. DR uses flat panel detectors for capturing the image. DR has its own advantages such as faster acquisition, and contrast adjustment even after the exposure has been made. This creates the need for optimization of patient doses and establishments of guidance levels for radiation protection of patients (Matthews et al., 2009). Doses can be monitored by measuring the kerma area product (KAP) or by calculating the entrance surface air kerma (ESAK). ESAK is measured at a point where X-ray beam enters the patient on the beam axis. It includes the backscatter factor (Zoetelief, 2005; IAEA, 2007). Published literature was reviewed and research gaps showed limited work in dose evaluation in skull radiography, in spite of being the common radiological exam performed (IAEA, 1995). Literature also showed that poor quality skull radiographs were obtained due to low technical standards used and the lack of expertise by the operator and sometimes resulting into repeat exposures. Repeat exposures account to the increased radiation dose (Jennett, 1980; Bell, 1971). The frequency of these examinations is also high (Desmet et al., 1979). Present study aims to calculate the ESAK values and estimate the effective doses in adult patients undergoing 
digital skull radiographic examinations. The skull $\mathrm{X}$ ray examinations with projection postero-anterior (PA) and lateral (Lat) were considered for the study.

\section{Materials and Methods}

Total 64 radiographic skull (PA and Lat) examinations were enrolled in the study (27 male and 64 female). Patient doses were calculated with the IAEA protocol (minimum 10 patients per radiographic examination) in a teaching hospital in Delhi, India for a period of 2 months (IAEA, 2007). Weight restriction criteria of $70 \pm 10 \mathrm{~kg}$ was considered and informed consent was taken. In order to compare our doses with other countries, the reference weight of $70 \pm 10 \mathrm{~kg}$ is required. Ethical approval was obtained from institutional ethical committee. A caliper scale was used for measuring patient thickness $\left(t_{p}\right)$. Demographic and technical data i.e., patient's weight, age, height, sex, tube current $(\mathrm{mA}), \mathrm{mAs}$, tube voltage $(\mathrm{kVp})$, exposure time (s), patient thickness and focus to detector distance (FDD) was recoded. Patient thickness (measured for each patient) and bucky thickness $(5 \mathrm{~cm})$ were subtracted from FDD to evaluate FSD. The ESAK was determined (equation 1) as described in international protocols (Gonzalez et al., 2004). Radiographic examinations were performed on digital radiography machine make GE healthcare. X-rays were performed by radiographers on duty. Quality control tests were performed before recording the data.

$$
\begin{aligned}
\mathrm{ESAK}= & \mathrm{TO} \times(\mathrm{mGy} / \mathrm{mAs}) \times \mathrm{mAs} \\
& \times(100 / \mathrm{FSD})^{2} \times \mathrm{BSF}
\end{aligned}
$$

Where,

$\begin{array}{ll}\text { ESAK } & : \text { entrance surface air kerma } \\ \text { TO } & : \text { tube output in } \mathrm{mGy} / \mathrm{mAs}, \\ \mathrm{mAs} & : \text { tube current } \mathrm{x} \text { exposure time, } \\ \mathrm{FSD} & : \text { the patient thickness and } \\ \mathrm{BSF} & : \text { the backscatter factor. }\end{array}$

The effective dose (equation 2) was evaluated using conversion coefficients from UK HPA -012 (Hart et al., 2010). Descriptive statistics of the collected data were performed in SPSS statistics 23.0 for windows.

$$
\begin{aligned}
\mathrm{E}(\mathrm{mSv})= & \mathrm{CV}_{\mathrm{ESAK}}\left(\mathrm{mSvmGy}^{-1}\right) \\
& \times \operatorname{ESAK}(\mathrm{mGy})
\end{aligned}
$$

\section{Results and Discussion}

Demographic information and technical parameters are presented in Table 1 . Table 2 presents mean $\pm S D$, median, $25^{\text {th }}$, and $75^{\text {th }}$ percentile values of ESAK ( $\mathrm{mGy}$ ). It also presents a comparison with $75^{\text {th }}$ percentile values of studies by Bhupendra et al. and Satish et al. in India, and UK 2010

\begin{tabular}{|c|c|c|c|c|c|c|c|c|}
\hline \multirow{3}{*}{$\begin{array}{l}\text { This study } \\
\text { Examination }\end{array}$} & \multicolumn{5}{|c|}{ ESAK (mGy) } & \multirow{2}{*}{$\begin{array}{l}\text { UK } \\
2010 \\
\text { HPA-034 }\end{array}$} & \multirow{2}{*}{$\begin{array}{l}\text { Bhupendra } \\
\text { et al. } \\
2018 \\
\text { India }\end{array}$} & \multirow{2}{*}{$\begin{array}{l}\text { Satish } \\
\text { et al. } \\
2017 \\
\text { India }\end{array}$} \\
\hline & \multirow{2}{*}{ mean $\pm S D$} & \multirow{2}{*}{ Min- max } & \multirow{2}{*}{25 percentile } & \multirow{2}{*}{ Median } & \multirow{2}{*}{75 percentile } & & & \\
\hline & & & & & & \multicolumn{3}{|c|}{ 75th Percentile } \\
\hline Skull PA & $0.471 \pm 0.125$ & $0.272-0.848$ & 0.387 & 0.454 & 0.55 & 1.8 & $* *$ & 4.7 \\
\hline Skull Lat & $0.263 \pm 0.077$ & $0.133-0.441$ & 0.192 & 0.252 & 0.324 & 1.1 & 2.38 & $* *$ \\
\hline
\end{tabular}

Table 1: Patient demographic information and technical factors.

\begin{tabular}{|l|l|l|l|}
\hline Examination & & Skull PA & Skull Lat \\
\hline No. of exposures $(\mathrm{n})$ & & 30 & 34 \\
\hline \multirow{3}{*}{ Gender } & $\mathrm{M}$ & 12 & 15 \\
\cline { 2 - 4 } & $\mathrm{F}$ & 18 & 19 \\
\hline \multirow{3}{*}{ age (years) } & mean & 36.67 & 35.41 \\
\cline { 2 - 4 } & range & $18-52$ & $19-60$ \\
\hline \multirow{3}{*}{ Height $(\mathrm{cm})$} & mean & 63.83 & 65 \\
\cline { 2 - 4 } & range & $60-80$ & $60-80$ \\
\hline \multirow{3}{*}{ m A s } & mean & 158 & 161 \\
\cline { 2 - 4 } & range & $140-174$ & $140-170$ \\
\hline \multirow{2}{*}{ FSD $(\mathrm{cm})$} & mean & 4.09 & 3.24 \\
\cline { 2 - 4 } & range & $2.0-7$ & $1.62-5.54$ \\
\hline Patient thickness $(\mathrm{cm})$ & mean & 76 & 79 \\
\hline \multirow{2}{*}{$\mathrm{kV}$} & mean & 80 & $70-86$ \\
\hline FDD $(\mathrm{cm})$ & mean & 100 & 100 \\
\hline
\end{tabular}

Table 2: ESAK (mGy) values obtained in the study and comparison with published literature. 
Table 3: Effective Dose, E (mSv) in present study and comparison with UK 2011.

\begin{tabular}{|l|l|l|l|l|l|l|}
\hline \multirow{2}{*}{$\begin{array}{l}\text { This study } \\
\text { Examination }\end{array}$} & \multicolumn{5}{|c|}{ Effective Dose, E(mSv) } & $\begin{array}{l}\text { UK } \\
2011\end{array}$ \\
\cline { 2 - 7 } & mean & SD & Min-max & Median & 75 percentile & mean \\
\hline Skull PA & 0.0061 & 0.0016 & $0.0035-0.0110$ & 0.0059 & 0.0071 & 0.02 \\
\hline Skull Lat & 0.0031 & 0.0009 & $0.0015-0.0052$ & 0.003 & 0.0038 & 0.016 \\
\hline
\end{tabular}
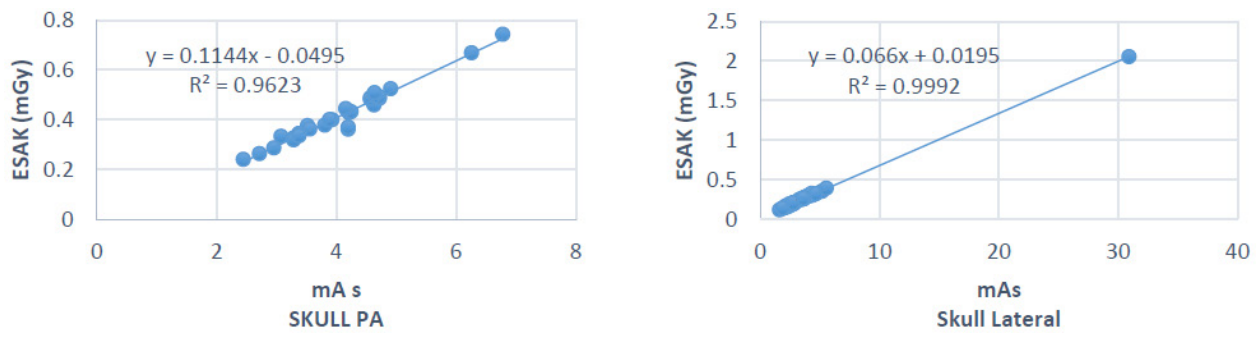

Figure 1: The relationship (linear) between $\mathrm{mAs}$ and ESAK (mGy)

review (Rana, 2018; Uniyal, 2017; Hart, 2010). Table 3 presents the effective doses its comparison with mean doses of UK 2011. The linear relationship observed between $\mathrm{mAs}$ and ESAK is presented in figure 1 with $\mathrm{R}^{2}$ values. $\mathrm{R}^{2}$ values calculated were 0.9623 and 0.9992 for skull PA, skull Lat.

The ESAK values of skull PA and skull LAT are lower in comparison with earlier studies. On comparing doses of present study with UK HPA-CRCE-034, the percentage decrease of radiation dose is found to be $69 \%$ and $70 \%$ for skull PA and skull Lat. UK report HPA-CRCE-034 is a national survey with the mean patient weight of UK of $70 \mathrm{~kg}$ (Hart et al., 2010). Our study presents ESAK values in digital radiography. The mean $\mathrm{kVp}, \mathrm{mAs}$, tube filtration $(\mathrm{mm} \mathrm{Al})$ used for radiographic examinations in UK HPA-CRCE-034 are skull PA (72kvp, 20mAs) and skull Lat $(66 \mathrm{kvp}, 11 \mathrm{mAs})$. It can be seen that a lower $\mathrm{mAs}$ is applied in present study for skull PA and skull Lat. Digital radiography uses flat panel detectors, which results in dose reduction (Hernamm et al., 2002). This reduction in patient dose by using flat panel detectors is also reported by Sjoholm et al., and Metaxas et al., (Sjöholm, 2005; Metxas, 2019). Comparing present study results with similar study in India by Bhupinder $e t a l$, it is observed that for skull Lat the percentage decrease of radiation dose is found to be $86 \%$ (Rana et al., 2018). The mean patient weight of both the studies is comparable. Satish et al., presented DRLs via dose survey of mixed type of X-ray machines. For skull PA, the percentage decrease of radiation dose is found to be $88 \%$ (Uniyal et al., 2017). Doses below DRLs indicates radiographic practice in acceptable limits, but dose audits are required to maintain ALARA. Present study provides initial baseline data for radiation protection and optimization of doses and suggests timely dose audits in digital radiography.

Limitations: Radiation dose assessment was carried out in skull radiography in present study. ESAK values could further be measured in other common radiographic examinations.

\section{Conclusion}

The study aimed to calculate the ESAK, and effective dose values in digital skull radiographic examinations. The results obtained are compared with ESAK and effective dose values of UK and studies in India. Study also presents the current radiographic practices in skull digital radiography. The obtained doses are lower than that of published literature which is attributed to DR system, good radiographic practices and application of dose reduction techniques. Consistent dose optimization can be achieved by timely dose audits. The values obtained in this study may further contribute to future LDRLs.

Conflict of interest: The authors declare no conflict of interest.

Funding source: None

\section{References}

Atomic energy Regulatory Board (2001). Safety Code for medical diagnostic X-ray equipment and installation. 
No. AERB/SC/MED-2 (Rev.1) (Mumbai, India: atomic energy regulatory board).

Atomic energy Regulatory Board (2016). Safety code for radiation safety in manufacture, supply and use of medical diagnostic X-ray equipment. No. AERB/ RFMED/SC-3 (Rev. 2).

Bell R.S. \& Loop J.W. (1971). The utility and futility of radiographic skull examination for trauma. New England Journal of Medicine, 284(5), 236-239. https:/doi.org/10.1056/NEJM197102042840504

Hart, D., Hillier, M.C. \& Wall, B.F. (2007). Doses to patients from radiographic and fluoroscopic X-ray imaging procedures in the UK-2005 review HPARPD-029. HPA ISBN: 978-0-85951-600-6.

De Gonzalez, A.B. \& Darby, S. (2004). Risk of cancer from diagnostic X-rays: estimates for the UK and 14 other countries. The lancet, 363(9406), 345-351. https://doi.org/10.1016/S0140-6736(04)15433-0

DeSMET, A.A., Fryback, D.G. \& Thornbury, J.R. (1979). A second look at the utility of radiographic skull examination for trauma. American Journal of Roentgenology, 132(1), 95-99. https://doi.org/10.2214/ajr.132.1.95

European Commission (EC) (2014). Diagnostic Reference Levels in Thirty-six European Countries Part 2/2. Radiation protection No. 180. Luxembourg: Publications Office of the European Union.

Gray, J.E., Archer, B.R., Butler, P.F., Hobbs, B.B., Mettler, F.A., Pizzutiello, R.J., Schueler, B.A., Strauss, K.J., Suleiman, O.H. \& Yaffe, M.J. (2005). Reference values for diagnostic radiology: application and impact. Radiology, 235(2), 354-358. https://doi.org/10.1148/radiol.2352020016

Hall, E.J. \& Brenner, D.J. (2008). Cancer risks from diagnostic radiology. The British journal of radiology, 81(965), 362-378.

https://doi.org/10.1259/bjr/01948454

Hart, D., Hillier, M.C. \& Wall, B.F. (2002). Doses to patients from medical X-ray examinations in the UK2000 review. Chilton, UK. National Radiological Protection Board.

Hart, D., Wall, B.F., Hillier, M.C. \& Shrimpton, P.C. (2010). Frequency and collective dose for medical and dental X-ray examinations in the UK, 2008. Health Protection Agency.

Hart, D., Hillier, M. \& Shrimpton, P. (2010). Doses to patients from radiographic and fluoroscopic X-ray imaging procedures in the UK. Chilton: Health Protection Agency Centre for Radiation, Chemical and Environmental Hazards.
Herrmann, K., Bonel, H., Stäbler, A., Kulinna, C., Glaser, C., Holzknecht, N., Geiger, B., Schätzl, M. \& Reiser, M. (2002). Chest imaging with flat-panel detector at low and standard doses: comparison with storage phosphor technology in normal patients. European radiology, 12(2), 385-390. https://doi.org/10.1007/s00330-001-1166-4

International Atomic Energy Agency (IAEA) (2007). Dosimetry in diagnostic radiology: An International Code of Practice IAEATRS. No 457. Vienna: IAEA (2007).

International Atomic Energy Agency (IAEA) (2004). Optimization of the radiological protection of patients undergoing radiography, fluoroscopy and computed tomography. Vienna. IAEA (2004).

International Atomic Energy Agency (IAEA) (1995). Radiation doses in diagnostic radiology and methods for dose reduction. IAEA-TECDOC-796. Vienna: IAEA, (1995).

Jennett, B. (1980). Skull X-rays after recent head injury. Clinical radiology, 31(4), 463-469. https://doi.org/10.1016/S0009-9260(80)80195-4

Martin, C. J. (2007). The importance of radiation quality for optimisation in radiology: Biomedical Imaging and Intervention Journal, 3(2), e38. https://doi.org/10.2349/biij.3.2.e38

Matthews, K. \& Brennan, P.C. (2009). The application of diagnostic reference levels: General principles and an Irish perspective. Radiography, 15(2), 171-178. https://doi.org/10.1016/j.radi.2008.03.001

Metaxas, V.I., Messaris, G.A., Lekatou, A.N., Petsas, T.G. \& Panayiotakism, G.S. (2019). Patient doses in common diagnostic X-ray examinations. Radiation protection dosimetry, 184(1), 12-27. https://doi.org/10.1093/rpd/ncy169

Radiation Protection 109 (1999). Guidance on diagnostic reference levels (DRLs) for Medical Exposures. Luxembourg. European Communities: 1999.

Rana, B.S., Kumar, S., Sandhu, I.S. \& Singh, N.P. (2018). Dosimetry of Adult And Pediatric Patients For Common Digital Radiography Examinations. Radiation protection dosimetry, 179(4), 349-357. https://doi.org/10.1093/rpd/ncx293

Samei, E., Dobbins, I.I.I. J.T., Lo, J.Y. \& Tornai, M.P. (2005). A framework for optimising the radiographic technique in digital X-ray imaging. Radiation Protection Dosimetry, 114(1-3), 220-229. https://doi.org/10.1093/rpd/nch562

Sjöholm, B., Geijer, H. \& Persliden, J. (2005). Impact of digital imaging on radiation doses to the patient 
during X-ray examination of the urinary tract. Acta Radiologica, 46(6), 657-661.

https://doi.org/10.1080/02841850510021616

Uffmann, M. \& Schaefer-Prokop, C. (2009). Digital radiography: The balance between image quality and required radiation dose. European Journal of Radiology, 72(2), 202-208.

https://doi.org/10.1016/j.ejrad.2009.05.060

UNSCEAR (2010). Sources and effects of ionizing radiation. 2008 UNSCEAR report to the general assembly with scientific annex.

Uniyal, S.C., Chaturvedi, V., Sharma, S.D. \& Raghuvanshi, S. (2017). Estimation of entrance surface air kerma due to diagnostic X-ray examinations of adult patients in Uttarakhand, India and establishment of local diagnostic reference levels. Australasian physical $\&$ engineering sciences in medicine, 40(3), 687-694. https://doi.org/10.1007/s13246-017-0577-8
Vañó, E., Miller, D.L., Martin, C.J., Rehani, M.M., Kang, K., Rosenstein, M., Ortiz-López, P., Mattsson, S., Padovani, R. \& Rogers, A. (2017). ICRP Publication 135. Diagnostic Reference Levels in Medical Imaging. Annals of the ICRP, 46(1), 1-144.

Wall, B.F., Haylock, R., Jansen, J.T.M., Hillier, M.C., Hart, D. \& Shrimpton, P.C. (2011). Radiation risks from medical X-ray examinations as a function of the age and sex of the patient. Health Protection Agency, Centre for Radiation, Chemical and Environmental Hazards Chilton, Didcot Oxfordshire.

Zoetelief, J., Dance, D.R., Drexler, G., Järvinen, H., Rosenstein, M., Allisy-Roberts, P., Bosmans, H., Moretti, C.J., Van Dam, J., Vañó, E., Wall, B.F., Wambersie, A., DeLuca, P.M. (2005). Patient dosimetry for $\mathrm{X}$ rays used in medical imaging. Journal of the Icru, 5, 1-113. 


\section{旬 \\ CHITKARA}

\section{Journal of Multidisciplinary Research in Healthcare}

Chitkara University, Saraswati Kendra, SCO 160-161, Sector 9-C, Chandigarh, 160009, India

Volume 5, Issue 2

April 2019

ISSN 2393-8536

Copyright: [ $₫ 2019$ Chanchal Kaushik et al.] This is an Open Access article published in Journal of Multidisciplinary Research in Healthcare (J. Multidiscip Res. Healthcare) by Chitkara University Publications. It is published with a Creative Commons Attribution- CC-BY 4.0 International License. This license permits unrestricted use, distribution, and reproduction in any medium, provided the original author and source are credited. 